\title{
DE LOS ESPEJOS, EL FÉNIX Y LA MUJER SERÁFICA: IMÁGENES PLATÓNICAS DEL ALMA EN LAS OBRAS DE MARGUERITE PORETE, HADEWIJCH Y MECHTHILD VON MAGDEBURG*
}

\author{
Pablo Acosta-García \\ Heinrich-Heine-Universität Düsseldorf
}

\section{RESUMEN}

En este ensayo estudiaremos la imagen del espejo en algunas autoras de literatura mística femenina europea de los siglos XIII y XIV (Mechthild von Magdeburg, Hadewijch van Brabant y Marguerite Porete), sobre todo en su vinculación con el imaginario específicamente platónico que la relaciona con el alma. Estamos especialmente interesados en aclarar la coherencia de las preconcepciones antropológicas, médicas y teológicas que subyacen en el uso de esa imagen en concreto, sobre todo en los desarrollos concernientes al (auto-)conocimento como forma de deificación (theosis). De manera complementaria, estudiamos las relaciones que se establecen entre este imaginario y el de la denominada «mystique courtoise», en particular con el tema de la fuente de Narciso.

Palabras clave: Mechthild von Magdeburg, Hadewijch, Marguerite Porete, alma, platonismo, deificación.

\author{
ON MIRRORS, THE PHOENIX AND THE SERAPHIC WOMAN: \\ PLATONIC IMAGES OF THE SOUL IN THE WORKS \\ OF MARGUERITE PORETE, HADEWIJCH \\ AND MECHTHILD VON MAGDEBURG
}

\section{Abstract}

The main focus of this essay is the study of the image of the mirror in the works of religious women from the 13th and 14th centuries (Mechthild von Magdeburg, Hadewijch van Brabant and Marguerite Porete), especially regarding the Platonic tradition which links this image with the soul. I will examine fragments of their literary work in order to discuss some physiological, anthropological and theological preconceptions implied in the use of the mirror-image, especially those developments concerning self-knowledge and deification (theosis). Additionally, I analyze the relationships between the mirror and the "mystique courtoise," particularly with the theme of the Fountain of Narcissus.

Keywords: Mechthild von Magdeburg, Hadewijch, Marguerite Porete, Soul, Platonism, Deification. 
Aimer, c'est voir! Aimer, c'est connaître!

(R. Javelet, Image et Ressemblance au douzième siecle, p. 429)

\section{INTRODUCCIÓN}

Lo que hoy llamamos mística, como tan certeramente estableciera Michel de Certeau, se caracteriza por componer una fábula en su sentido etimológico, un modus loquendi particular, una «manera de hablar» determinada, en suma ${ }^{1}$. Esta manera, que supone una serie de elecciones no meramente lingüísticas, sino también imaginarias, es lo que el mismo Certeau definió como las «huellas de una lucha $»^{2}$ : el texto místico no contiene otra cosa que los despojos de una batalla que ha sido sostenida entre la experiencia y el lenguaje. Recorrer los textos de autoras que pertenecen a un «movimiento religioso» determinado (el de los siglos XIII y XIV en ambientes mendicantes, más exactamente beguinales) ${ }^{3}$ es encontrarte con el consabido lenguaje amatorio del que hablaré más o menos ampliamente en las próximas páginas, pero en un desierto en el que las esfinges, lamias o quimeras (como figuras clásicas) no aparecen. Eso sí, existe el fénix. En el título elegido nombro a este animal de bestiario que, junto al águila, suele aparecer en las revelaciones de las místicas aludiendo a la resurrección de Cristo ${ }^{4}$. Pero ¿en qué texto religioso medieval no aparecen animales de ese "alfabeto simbólico», como lo denominó Francesco Zambon?5. No he querido acogerme a las bonanzas de estas antologías animadas ni, en general, a los infinitos materiales que me hubieran proporcionado entender las Escrituras como una fuente de mitos judeocristianos, sino plantear una pregunta, creo, de respuesta más compleja. ¿Por qué en la mística bajomedieval femenina, al menos en el canon mínimo (y creciente) que hemos podido establecer desde los ańos ochenta

* Este artículo es fruto de la invitación del doctor José Antonio Ramos Arteaga para dar una conferencia en el marco del seminario el Instituto Universitario de Estudios Medievales y Renacentistas (IEMYR) de la Universidad de La Laguna en el año 2019. Le agradezco profundamente tanto esta invitación, que me permitió volver a mi universidad de origen después de tantos años, como su magisterio extendido en el tiempo, en tantas tardes y noches de encendida, seráfica conversación. Asimismo, quiero expresar mi gratitud a los restantes miembros del IEMYR por dos días de ininterrumpido intercambio intelectual.

1 M. de Certeau, La fábula mistica. Madrid, Siruela, 2006.

2 Idem, p. 117.

3 Tomo la expresión «movimiento religioso» en el sentido de H. Grundmann, Religious Movements in the Middle Ages, Indiana, University of Notre Dame Press, 1995 (1. ${ }^{\mathrm{a}}$ ed. 1935). Sobre las beguinas de las que hablaré en las siguientes páginas, v. B. McGinn, The flowering of Mysticism. Men and Women in the New Mysticism (vol. in de la serie The Presence of God. A History of Western Christian Mysticism, 1200-1350), New York, Crossroad, 1998. Sobre las comunidades europeas de beguinas, v. W. Simons, Cities of Ladies: Beguines Communities in the Medieval Low Countries, 12001565, Philadelphia, University of Pennsylvania Press, 2001.

${ }^{4}$ V., por ejemplo, P. García Acosta, Poética de la visibilidad en el Mirouer des simples ames de Marguerite Porete, tesis doctoral, Barcelona, Universitat Pompeu Fabra, 2009, pp. 173-174.

5 F. Zambon, L'alfabeto simbolico degli animali, Milano-Trento, Luni ed., 2001. 
del siglo xx hasta ahora, no hay apenas imaginería clásica? Y una pregunta derivada de esta: ¿por qué en los siglos inmediatamente posteriores a la aetas Ovidiana en un grupo de autoras que, como veremos a continuación, utiliza la expresión del amor profano para expresar su relación con la divinidad no existen casi alusiones a la mitología clásica? ${ }^{6}$. O, mejor, ¿`eguro que es así?

Mi propuesta es revisar en las siguientes páginas un símbolo esencial, el espejo, en la literatura de estas mujeres, lo que nos coloca frente a la dificultad de analizar una de esas imágenes fundamentales en la cultura occidental que se encuentran cerca de la ubicuidad de símbolos como la montańa o el árbol y que, en la Edad Media europea, poseen una tradición específica, la del platonismo cristiano7. Esta propuesta de estudio estuvo motivada en principio por la perplejidad que me causaba el hecho de que en gran parte de la mística occidental al menos a partir de Orígenes y sus Homilias sobre el Cantar de los cantares, existiera la tradición de vincular el lenguaje erótico con la vivencia o la búsqueda de lo divino, frente a una generalizada ausencia de mitos clásicos ${ }^{8}$. Es este el caso de las beguinas, que, como bien ha mostrado Barbara Newman, utilizan un lenguaje que sin duda hace uso del Cantar como uno de sus tesoros expresivos, pero que lo sobrepasa frente a la mística por ejemplo cisterciense, ya que utiliza el lenguaje de la fin'amors, el lenguaje de un amor profano para no simplemente hablar de lo divino, sino para anhelarlo, desarrollando un verdadero canto del deseo'. Por ejemplo, un fragmento inicial de uno de los poemas en verso (Mengeldichten) de Hadewijch, beguina brabantina del siglo XIII de cuya vida muy poco conocemos, aunque se hayan conservado sus visiones, sus poemas en prosa y verso y muchas de sus $\operatorname{cartas}^{10}$ :

No importa cuál sea la estación:/en cada época del año/experimenta alegría y miedo, ambos, / quien por la causa del Amor sufre en el exilio. / Qué alegremente estaría con su Amado / para endulzar sus aciagos días. I ‘Ay de míl' grita, porque aún no es suya la felicidad. / Mas suaviza su queja, porque de seguro llegará: / 'Todo tuyo soy: ¡Amada, / sé toda mía, si te place!’

${ }^{6}$ Para la expresión aetas ovidiana, acuñada por Ludwig Traube para referirse al siglo XII, v. L. VINGe, The Narcissus Theme in Western European Literature up to Early 19th century, Lund, Gleerups, 1967, pp. 55-56.

${ }^{7}$ M. Viller et al., Dictionnaire de Spiritualité ascétique et mistique. Doctrine et Histoire, Paris, Beauchesne, 1937, vol. 10, s. v. «Miroir», columnas 1290-1303, esp. 1291.

${ }^{8}$ A.W. Astell, The Song of the Songs in the Middle Ages, Ithaca y London, Cornell University Press, 1990, pp. 137-167.

9 B. Newman, From the Virile Woman to the Woman Christ, Philadelphia, University of Pennsylvania Press, 1995.

${ }_{10}$ Tomo la traducción de H. de Amberes y B. de Nazaret, Flores de Flandes, trad. Carmen Ros y Loet Swart, Madrid, BAC, 2001. Los versos originales (editados en Hadewjich, Strofische gedichten, vol. 1, ed. J. van Mierlo, Standaard-Boekhandel, 1942, 25: I, p. 160) rezan: «In allen tiden vanden jare, / Hoe dat el metten tide si, / Hevet hi bliscap ende vare/Die doghet allende o $m$ minne vri, / Ende gherne dan lieve ware bi / Om te suetenne sine alendeghe daghe. / Dats noch niet en es, doet roepen: ay mi! / Dat wesen sal dat ceste claghen: / 'Ay ic ben al di; lief, wes al mi, / Alset di behaghe!'». 
Estas líneas, la primera estrofa de la canción xxv de Hadewijch, nos ubican en ese lenguaje en el que el canto a la divinidad se realiza a través del lenguaje del deseo amatorio. Por supuesto, debemos leer los dos primeros versos como una alusión a la Primavera trovadoresca que en este caso se transgrede, ya que no se habla simplemente de la estación que propicia el amor, sino de un amor que el alma que lo conoce experimenta siempre y que, por tanto, en cualquier momento hace amar y temer a la vez. Sin duda hay un término clave en este temor, que es el concepto omnipresente en una mística fuertemente marcada por el neoplatonismo como es la del siglo XIII, que es la palabra «exilio». La concepción es, como digo, puramente neoplatónica y la encontramos en un autor tan temprano como Plotino, que la encarna en el mito de Ulises ${ }^{11}$ :

Zarparemos como cuenta el poeta (con enigmática expresión, creo yo) que lo hizo Ulises abandonando a la maga Circe o a Calipso, disgustado de haberse quedado pese a los placeres de que disfrutaba a través de la vista y la gran belleza sensible con que se unía. Pues bien, la patria nuestra es aquella de la que partimos y nuestro Padre está allá.

Este fragmento se establece sobre las mismas coordenadas existenciales que el exilio de Hadewijch: hemos abandonado nuestra patria verdadera, donde habita el Padre (que en Plotino debemos identificar con el Uno del que emanamos), aunque el retorno a la Patria nunca sea total y solo se complete con el retorno al Nous. Estamos, por tanto, en el exilio de la carne y la materia. Frente a un autor del mundo clásico como Plotino, este mito de Ulises como retorno no se encuentra en las autoras místicas de los siglos XIII y XIV, sino que el redditus se figura a la manera cristiana a través de la imagen de la peregrinación, de la que quizá la imagen prototípica sea la peregrinación dantesca en la Commedia ${ }^{12}$. En este sentido, nos encontramos con una cristianización del imaginario mítico-escatológico.

Por último, para acabar con este fragmento, fijémonos en que el diálogo que entre el alma y la divinidad se produce está relacionado con lo que Paul Ricoeur llamará la «metáfora nupcial», por la que la poesía amatoria (también a lo divino) establece un juego de presencia-ausencia que sirve tanto para calmar como para acrecentar el deseo y, por tanto, el dolor y el canto, pero que al estar mediada por la idea de exilio entendemos que estamos en un contexto más específico que simplemente amatorio del Cantar de los cantares, estableciendo una tipología que Barbara Newman, en un capítulo ya clásico, denomina mística cortés («mystique courtoise») ${ }^{13}$.

11 Plotino, Enéadas I, 6: 8, trad. J. Igal, Madrid, Gredos, 1982.

12 Para un ejemplo de esta figuración, v. H. De Amberes y B. De Nazaret, Flores de Flandes, p. 273 o, relacionado con el ascenso y la revelación frente a Ítaca, p. 94.

13 P. Ricoevr, «La metáfora nupcial», en P. Ricoeur y A. LaCocque, Pensar la Biblia, Barcelona, Herder, 2001. Por otro lado, Newman, From the Virile Woman, sobre todo, pp. 137-139. Esta estudiosa define el término como una creación específica de las beguinas del siglo XIII (p. 137), que combina el esquema y las formas amorosas de la denominada Brautmystik, la mística nupcial, con las de la fin'amors (p. 138). 
Este sería el lenguaje expresivo de, fundamentalmente, cuatro autoras relacionadas con las formas de vida beguinales, pero que denotan una formación literaria cortés que las relaciona con una educación aristocrática: la misma Hadewijch, Marguerite Porete, Mechthild von Magdeburg (primero beguina, después monja cisterciense) y Beatrijs van Nazareth (criada por beguinas) ${ }^{14}$. Como la estudiosa estadounidense ha probado en otro lugar, no solo en los trovadores, sino en el Roman de la rose, encontramos gran parte de la tradición expresiva que contribuyó a conformar el imponente tratado espiritual que supone el Mirouer des simples ames de la beguina a caballo entre los siglos XIII y XIV Marguerite Porete ${ }^{15}$. Muy resumidamente podríamos afirmar que el libro escrito por Marguerite es la descripción fragmentada de una escalera de amor que se pretende enseñar a un auditorio contemplativo. El fin de esta escalera es azuzar al receptor a emprender un viaje de retorno, i. e. un redditus, a la simplicidad divina, siendo la fusión con esta divinidad la meta última del itinerario $^{16}$. Este libro considerado herético supuso el primer auto de fe inquisitorial en Francia, cuando se quemó a su autora junto a copias de su libro en la Place de Greve de París ${ }^{17}$.

En primer lugar a nivel expresivo, tal y como apunta Newman en la obra citada, es fundamental entender que el Roman de la rose proporciona a Marguerite no solo la forma alegórica que articula todo el tratado (en síntesis, una discusión entre Razón y Amor, cuya conclusión es que debemos negar a Razón para tomar el camino de Amor, que, a su vez, debe ser negado para tomar el camino de la Nada), sino también, quizá, la imagen que fundamentó la concepción del propio "Espejo» de las almas simples más allá de la propia concepción del género, el speculum ${ }^{18}$. La estudiosa estadounidense nos habla de este libro, de este espejo, como de un espejo de Narciso que contiene la posibilidad de encontrar un espejo eterno. Si esta visión está, como creo, fundamentada, Marguerite Porete, la mujer que fue ejecutada el 1 de junio de 1310, habría escrito un espejo de amor (es decir, un tratado de erótica didáctica) en el que los amantes (es decir, las almas que buscan a Dios) podrían mirarse para amar y recibir así los dones de la divinidad. Sin duda esto es así, pero también Marguerite escribió que este espejo debía romperse, y que detrás de él

${ }^{14}$ Para una introducción a estas figuras, v. V. Cirlot y B. Garí, La mirada interior. Escritoras místicas y visionarias en la Edad Media, Madrid, Siruela, 2008 (1. ${ }^{a}$ ed. 1999).

15 B. Newman, «The Mirror and the Rose: Marguerite Porete's Encounter with the Dieu d'Amours", en R. Blumenfeld-Kosinski, D. Robertson y N. Warren, The Vernacular Spirit: Essays on Medieval Religious Literature, New York, Palgrave, 2002, pp. 105-123. Este capítulo después se reimprimió con el mismo título pero con ańadidos, en su Medieval Crossover: Reading the Secular against the Sacred, Indiana, University of Notre Dame Press, 2013.

${ }_{16}$ Analizo pormenorizadamente este imaginario en García Acosta, Poética de la visibilidad.

17 V. S.L. Field, The Beguine, the Angel, and the Inquisitor: The Trials of Marguerite Porete and Guiard of Cressonessart, Notre Dame, Notre Dame University Press, 2002.

18 V. R. Bradley, «Backgrounds of the Title Speculum in Mediaeval Literature». Speculum, vol. 29, 1 (January 1954), pp. 100-115. 
encontraríamos otro, que debería atravesarse para llegar a la fusión con lo divino. Hablemos del primero de ellos, el espejo cortés de Narciso ${ }^{19}$.

\section{LE MIRÖER PERILLEUS}

El primer paso para desarrollar esto que digo es contextualizar el mito en el Roman de la rose, al menos de una manera mínima ${ }^{20}$. Como es bien sabido, este motivo se encuentra en la primera parte de la obra, la firmada por Guillaume de Lorris, en la que el amante penetra en un jardín, en el que ve, entre una caterva de personajes alegóricos, corteses, virtuosos y danzantes, al mismo Dios del Amor (Dieu d'Amours), que lo vigila desde que detecta su presencia y lo persigue por el jardín por el que el enamorado pasea. Además de animales paradisiacos y gran variedad de verdura, el amante se fija en un elemento fundamental que se encuentra bajo un gran pino: la fuente de Narciso, en la que el doncel perdió la vida, según el narrador "perdiendo de dolor su sentido», es decir, «loco de dolor» $»^{21}$. Esa fuente está definida en un famoso sintagma como le miröer perilleus, el espejo peligroso ${ }^{22}$. Como leeremos a continuación, atravesando este reflejo, en el fondo de la fuente yacen dos piedras de cristal, a las que el sol ilumina con sus brillantes rayos, haciendo que cambien de color y convirtiéndolas en espejos que reflejan todo el jardín ${ }^{23}$ :

En lo más hondo de aquella corriente/ había dos piedras que eran de cristal, / las cuales miré con gran atención. [...] / Cada vez que el sol, que ilumina todo, / envía a la fuente sus brillantes rayos / y su claridad desciende hacia abajo, / de aquellos cristales más de cien colores / van apareciendo, pues la luz del sol/ hacen que se pongan

${ }^{19}$ La contraposición espejo mimético frente a espejo divino (transformativo) es ya platónica: M. Viller et al, Dictionnaire de Spiritualité ascétique et mistique. Doctrine et Histoire, Paris, Beauchesne, 1937, vol. 10, s. v. «Miroir», columna 1301. Para nuestro caso, el contraste Mirouer-libro como espejo de Narciso frente al mirëor pardurable como simplicidad divina está esbozado en Newman, «The Mirror and the Rose», pp. 112-113. A su vez, para la idea del espejo que debe ser destruido o traspasado en el Mirouer, v. MüLler, Marguerite Porete et Marguerite d'Oignt, p. 34.

${ }^{20}$ V. Vinge, The Narcissus Theme, pp. 78-88.

${ }^{21}$ La traducción castellana es G. DE Lorris y Jean DE Meun, Roman de la rose, trad. Juan Victorio, Madrid, Cátedra, 1998, v. 1502. El original reza: «Il perdi d'ire tout le sens», v. nuestra nota 23.

${ }^{22}$ La bibliografía sobre este espejo es muy amplia. Para los temas que estudiamos aquí, v. el tratamiento que la da G. Agamben, Estancias. La palabra y el fantasma en la cultura occidental, Valencia, Pre-textos, 2001, pp. 150-151.

23 «Où fons de la fontaine aval, / Avoit deux pierres de cristal / Qu'à grande entente remirai, [...] / Quant li solaus qui tout aguete, / Ses rais en la fontaine giete, / Et la clartés aval descent, / Lors perent colors plus de cent/Où cristal, qui por le soleil/ Devient ynde, jaune et vermeil: / Si ot le cristal merveilleus/Itel force que tous li leus, / Arbres et flors et quanquaorne/Li vergiers, i pert tout aorne,». Tomamos la versión original de la bilingüe G. DE LORRIs, El libro de la rosa/Le roman de la rose, ed. C. Alvar, Madrid, Festín de Esopo, 1985, vv. 1536-1548. La traducción castellana es la de J. Victorio citada en nuestra nota 21. 
rojos y amarillos. / Estos son cristales de gran maravilla, / y tienen tal fuerza que todo el lugar, / árboles y flores y cuanto rodea/al jardín aquel, se refleja en ellos.

No es mi intención desgranar aquí las interpretaciones que se le han dado a este manantial desde el mito ovidiano a la Edad Media, sino fijarme en la interpretación de la misma que a mi parecer es la más plausible en el contexto del Roman de la rose. Esta se encuentra en las Stanze de Giorgio Agamben. Como sabemos, el trabajo original fue publicado en 1977 como manera de entender la poesía del Dolce stil nuovo en un contexto orgánico, en el que las alusiones a los ojos o al corazón del poeta no son simplemente metáforas o maneras verbales que se copian de la tradición trovadoresca, sino que forman parte de una red de alusiones que, sistematizadas, nos permiten entender que, como el mismo Agamben afirma, «el descubrimiento medieval del amor... es el descubrimiento de la irrealidad del amor, o sea de su carácter fantasmático $»^{24}$. El estudioso italiano comienza por repetir lo que otros ya habían afirmado antes, diciendo que lo que modernamente llamamos narcisismo, es decir, y reduciendo a sus mínimos básicos la interpretación freudiana, el «amor a sí mismo" o filautía, no es el pecado que se le adjudicaba a Narciso en la Edad Media ${ }^{25}$. Para Agamben, el quid de la inclusión de este mito en el jardín de amor y de considerar el reflejo en la fuente como el vehículo del proceso de enamoramiento subsiguiente está relacionado no con el amor al yo, sino simplemente con el amor a una imagen, es decir, con la concepción del amor como un proceso interno, que se inicia en la percepción (en general, a través de la vista, pero también a través del oído como en el caso del amor de lon $h^{26}$ ) y se desarrolla de manera psicofisiológica, causando una obsesión en el amante (aquella «immoderata cogitatio» de la que hablaba Andreas Capellanus), que en el caso de Narciso representa de manera arquetípica el simplemente enamorarse de una imagen ${ }^{27}$. Así, según la interpretación del italiano, que lee la fuente como parte de la fragmentación del amado típica de la alegoría medieval, esta representaría los ojos de amante, llenos de humor vítreo (agua) y penetrados por el sol (luz), y estos cristales en su fondo no serían otra cosa que la imaginación ${ }^{28}$. De esta manera este mirar daría inicio al proceso de enamoramiento, ya que son estos cristales los que le permiten al amante interiorizar a la rosa reflejada en ellos por vez primera.

La fantástica síntesis de la literatura médico-filosófica que realiza el italiano desgranando la lectura de autores como Galeno o Avicena nos permite entender a la manera medieval qué es la imaginación en este contexto, donde no es otra cosa que

${ }^{24}$ Agamben, Estancias, p. 148.

${ }_{25}$ V., por ejemplo, F. Goldin, The Mirror of Narcissus in the Courtly Love Lyric. Ithaca, New York, Cornell University Press, 1967, p. 9 o VInge, The Narcissus Theme, p. 16.

${ }^{26}$ V. V. Cirlot, «El amor de lejos y el valor de la imagen. Elaboración y negación del mito del amor en la Europa medieval», en J.I. De la Iglesia Duarte (coord.), Memoria, mito y realidad en la historia medieval. XIII Semana de Estudios Medievales, Nájera, 2002.

27 Esta lectura la avanzaba VINGE, The Narcissus Theme, pp. 47-55.

${ }^{28}$ En particular, las virtudes sensitiva e imaginativa. 
una de las cámaras cerebrales o cellae que permiten al ser humano recibir a través de sus sentidos el mundo externo ${ }^{29}$. Para apoyar esta visión reproduciré un pasaje de Hugo de San Víctor, citado por el italiano, cuya perspectiva me interesa especialmente, también porque sabemos que los victorinos son referencias innegables en la literatura beguinal. Dice Hugo de San Víctor ${ }^{30}$ :

En efecto, cuando la forma de la cosa sensible, tomada del exterior por medio de los rayos de la visión, es reconducida a los ojos por obra de la naturaleza y acogida por estos, se tiene la visión. Sucesivamente, pasando a través de las siete membranas de los ojos y de los tres humores... llega al cerebro y origina la imaginación. La imaginación, pasada de la parte anterior de la cabeza a la central, se pone en contacto con la misma sustancia del alma racional y provoca el discernimiento, ya tan purificada y hecha sutil como para poderse unir sin mediación con el mismo espíritu... La imaginación es, pues, una figura de la sensación, situada en la parte más alta del espíritu corpóreo y en la parte más baja del espíritu racional... En los animales irracionales no trasciende la celda fantástica, mientras que en los animales racionales llega hasta la celda racional, donde entra en contacto con la misma sustancia incorpórea del alma. Así pues subiendo de los cuerpos ínfimos y extremos hasta el espíritu corpóreo, hay una progresión a través del sentido y la imaginación, que están ambos en el espíritu corpóreo.

La gran variación que nos encontramos en la concepción de estos desarrollos perceptivo-psicológicos es enorme y su complejidad, desde las primeras explicaciones aristotélicas en De anima hasta el siglo XVII, es casi inabarcable, como ha demostrado Guillermo Serés en su magnífico La transformación de los amantes ${ }^{31}$. Simplemente me interesa aquí conectar el tema del reflejo en el espejo con el problema del apego al mundo a través de los placeres proporcionados por los sentidos, es decir, de los sentidos como nuestra única posibilidad de conocer lo externo, una posibilidad que debe purificarse para poder traspasar lo humano para llegar a lo divino. En efecto, este paso de la materia (o sea, de la multiplicidad) a las regiones del alma (más cercanas a la Unidad o a la simplicidad) replica un problema central del platonismo, al menos desde la escala de Diotima del Banquete ${ }^{32}$ : ¿cómo realizar el retorno del alma a la unidad, en términos cristianos a lo increado, si el ser humano, por definición está encerrado en un cuerpo? Hugo de San Víctor apunta a una solución a este problema en este fragmento: existe una región «en la parte más alta del espíritu corpóreo y en la parte más baja del espíritu racional» que conecta las inclinaciones corporales con la parte más noble del hombre. La respuesta de un neopla-

${ }^{29}$ Ver, por ejemplo, un diagrama medieval de la percepción en «Diagram of the corpus animatum (fragment)», Leipzig, Universitätsbibliothek, Fragm. lat. 242 (https://fragmentarium.ms/ overview/F-ljgt, consultado el 8/10/2019).

${ }^{30}$ Hugo de S. Víctor, De unione corporis et spiritus, apud Agamben, Estancias, p. 173.

31 G. Serés, La transformación de los amantes, Barcelona, Crítica, 1996.

32 Platón, El banquete, en Diálogos III, trad. M. Martínez Hernández. Madrid, Gredos, $1986,210{ }^{a}-212 .{ }^{a}$. 
tónico como Plotino es muy similar a la de Hugo de San Víctor: existe un lugar en el alma que nos reconecta con el Uno, más allá (más arriba) del alma intelectiva: el neoplatónico lo llamará centro del alma, y los seres humanos deben embarcarse en un proceso determinado para acceder a él ${ }^{33}$.

Lo que nos interesa en particular de esta visión de Hugo de San Víctor es la idea de que en el paso de celda a celda existe una suerte de denudatio, de purificación de la impresión fantasmática de todo aquello que presuponga lo externo, es decir, lo mundano o lo materia ${ }^{34}$. Como cita Agamben, «si no estuviera ya desnuda [la imagen], de todos modos quedaría desnuda, porque la virtud contemplativa la despoja de modo que ninguna afección material quede en ella ${ }^{35}$. Este juego de reflejos lleva al italiano a confirmar una evidencia teológico-platónica: el ser humano medieval cuando percibe el mundo solo es capaz de hacerlo a través de una serie de reflejos, por lo que cuando mira el mundo mira por espejo, per speculum. Solo somos capaces de percibir, abstraer, imaginar y, finalmente, comprender a través de una serie de especulaciones que se deben obligatoriamente intelectualizar en su sentido fuerte, para acceder a una comprensión desvinculada de la material y, por tanto, desde un punto de vista neoplatónico, del mal que reside en la materia. Es precisamente en la imposibilidad de negar el mundo externo en forma de imagen donde encontramos el tremendo peligro del espejo de Narciso en forma de idolatría. ¿Se encuentra, pues, este modo de amor en los escritos de nuestras beguinas de manera más o menos clara?

En un fragmento del Mirouer des simples ames a caballo entre los capítulos 119 y 120 , leemos lo siguiente ${ }^{36}$ :

[119] He dicho, dice esta alma, que Amor lo hizo escribir [este libro] por ciencia humana y por querer transformar mi entendimiento que me ponía obstáculos, como se muestra en este libro, pues Amor lo ha hecho despojando mi espíritu a través de los tres medios de los que hemos hablado [...].

[120] Verdad alaba a las almas que son asi [i.e., que moran en la nada] y dice:

¡Oh esmeralda y preciosa gema, / Verdadero diamante, reina y emperatriz, / vos dais todo por vuestra pura nobleza/sin pedir a Amor sus riquezas, / excepto el querer de su placer divino. / Nada es más justo conforme a la justicia, / pues esa es la verdadera vía/ de amor puro, que quiere mantenerla. / $\mathrm{Oh} !<$ Pozo $>$ profundo, sellada fuente $^{37}$, / donde el sol se esconde sutilmente, / emitís vuestros rayos -dice Verdadpor divina ciencia [...].

33 Es la concepción plotiniana del centro del alma la que, a través de las interpretaciones de Proclo y neoplatónicos posteriores, acaba creando la concepción del Grunt, del fondo o del abismo del alma, en el Maestro Eckhart. V. G. Della Volpe, La Mistica speculativa di maestro Eckhart: e i suoi rapporti storici. Cappelli, Bolońa, 1930.

${ }^{34}$ Agamben, Estancias, p. 142.

35 Idem, p. 143.

${ }^{36}$ M. Porete, El espejo de las almas simples, trad. B. Garí, Madrid, Siruela, 2005, p. 169.

37 El francés medio del denominado «Manuscrito de Chantilly» lee aquí «pfont et fontaine seellee». 
Los capítulos correlativos en el Mirouer siempre están interrelacionados. En el final del 119, vemos que el alma, entendiendo por esto el Alma que escribió el libro, es decir, un avatar de la autora y sus intenciones, un alma anonadada o que ha llegado a fundirse con la divinidad, considera a su entendimiento un "obstáculo» para anonadarse. Esto es esencial, pues debemos entender que de forma explícita el libro de Marguerite, como se nos comunica desde el «Prólogo», está concebido como una «imagen» (una representación, una reduplicación, falsa en muchos sentidos) de la divinidad que ha sido dada por Amor, es decir, por el mismo Dios ${ }^{38}$. El paralelismo con el amor profano es evidente: el enamoramiento se plantea a partir de la imagen, en este caso de la divinidad, pero la consecución de la transformación de los amantes no puede depender de la misma, porque ella se mueve en los ámbitos de lo humano, de lo corporal. A través de este tipo de amor, pues, debemos entender los versos siguientes al inicio del capítulo 120, casi al final de la primera parte: «iOh! <Pozo > profundo, sellada fuente, / donde el sol se esconde sutilmente, / emitís vuestros rayos - dice Verdad- por divina ciencia».

Estos contienen, a mi entender, una alusión velada a la fuente de Narciso del $\operatorname{Roman}^{39}$. El lenguaje amoroso-cortés en el que se expresa Verdad es un primer indicio de ello: ya afirmé anteriormente que la característica principal de la lengua amorosa beguinal es la de adoptar los giros y el imaginario de lo cortés. Si esto es así, la consideración normal del origen de esta fuente en el Cantar de los cantares, en alusión al versículo 4: 12 (subrayado mío): «Hortus conclusus soror mea, sponsa, hortus conclusus, fons signatus», a pesar de estar bien vista (el adjetivo signatus da cuenta de ello), puede complementarse con una fuente de amor profana. Lo que nos lleva a pensar en esta relación es la relación que se establece en los últimos versos entre esta fuente y el sol, que se esconde "sutilmente» en sus profundidades y desde donde «emite» (no recibe) los rayos de sabiduría. Esto es exactamente una inversión del sentido de los rayos de sol de la fuente de Narciso que leímos más arriba: el alma anonadada ya no recibe un input exterior en forma de luz, sino que desprende la luz, entendida como sabiduría divina, desde su propio interior hacia el mundo externo.

Si mi intuición es cierta estamos ante una reminiscencia por parte de Marguerite Porete de la imagen de la fuente profana de amor, precisamente para transgredir su significado habitual. Esta fuente de «amor puro» que nos presenta el Mirouer se contrapone al que, sin duda, es el espejo de Narciso, el espejo fantasmático en la tradición beguinal, un espejo que necesita de la fuerza del Amor para que el alma emprenda su camino hacia el anonadamiento y la divinidad. Es un espejo obsesionante (volvemos a la definición de Andreas Capellanus), pues se basa en la necesidad de la imagen como mediación entre la divinidad y el alma individual. Algo similar

38 Para un análisis de la concepción de la imago en el Prólogo, v. P. García AcostA, «Come insegnare a non vedere Dio: Visibilitá e negazione della imagine nella opera di Marguerite dicta Porete (m. 1310)», en La visione, ed. F. Zambon, Venezia, Medusa, pp. 107-130.

39 De la interrelación del Mirouer des simples ames y el Roman de la rose ha hablado Newman en «The Mirror and the Rose», pp. 105-123. Específicamente, sobre la fuente de Narciso en el Mirouer, v. pp. 110-111. 
había sido escrito Plotino, precisamente en el fragmento anterior al viaje de Ulises que leímos antes, hablando de Narciso como un impuro ${ }^{40}$ :

... al ver las bellezas corpóreas, en modo alguno hay que correr tras ellas, sino sabiendo que son imágenes y rastros y sombras, huir hacia aquella de la que estas son imágenes. Porque si alguien corriera en pos de ellas queriendo atraparlas como cosa real, le pasará como al que quiso atrapar una imagen bella que bogaba sobre el agua, como con misterioso sentido, a mi entender, relata cierto mito: que se hundió en la corriente y desapareció.

Así, repito, si en Roman de la rose la fuente de Narciso es el espejo de la imaginación, el Mirouer presenta un modelo en el que la sabiduría no se aprehende desde fuera, sino que proviene del anonadamiento del alma, desde dentro. Así, el espejo de Narciso debe romperse para que el camino del alma siga su rumbo hacia otro lugar que implica un paso de gigante: el espejo eterno de la divinidad.

\section{LE MIRËOR PARDURABLE}

Estamos ante dos espejos: uno, el de la imaginación, que refleja lo externo, lo material; el otro, que se hunde en el centro del alma. Para comenzar a hablar de este segundo espejo, citaré a Emanuele Coccia, un autor que no nos habla de Edad Media, pero sí de la imagen ${ }^{41}$ :

Cada vez que nos ponemos ante un espejo, de hecho, no ocurre solo la experiencia de redoblamiento narcisista de la consciencia entre un yo sujeto y un yo objeto. En el espejo, o mejor dentro del espejo, nuestra forma, nosotros mismos nos transformamos por un instante en algo que no conoce y que no vive, pero que permanece perfectamente sensible, que en realidad es lo sensible por excelencia. Mirándonos en el espejo nos convertimos, cada vez, dentro de él, en una realidad puramente imaginal, cuya única propiedad es la de ser sensible, una pura imagen sin consciencia y sin cuerpo.

En efecto, ser en un sentido fuerte, la persona reflejada en el espejo, dejando el cuerpo atrás, es la meta esencial a cumplir en esta vida por las beguinas platónicas que estamos estudiando. Si prescindimos de esta vertiente cortés que vamos desarrollando en nuestra búsqueda de reflejos, podemos decir que este espejo de la imaginación que multiplica las imágenes (símbolo de la innecesaria multiplicación de la materia en Platón y sus seguidores: el espejo de la mímesis) es tan necesario en el camino del alma hacia la divinidad como peligrosos pueden ser sus efectos. Veámoslo a través de un ejemplo bíblico típico, que posee claras resonancias neoplató-

40 Plotino, Enéadas i, 6: 8, trad. J. Igal, Madrid, Gredos, 1982.

${ }^{41}$ E. Coccia, La vita sensibile, Boloña, Il Mulino, 2011, p. 41, trad. mía. 
nicas. El lugar común es el famoso versículo de Pablo de Tarso de la I Epistola a los Corintios ${ }^{42}:$ «Videmus nunc per speculum in aenigmate: tunc autem facie ad faciem».

Desde el punto de vista paulino, existen dos modos de visión, entendiendo esta visión desde el punto de vista de la theoria platónica, es decir, lo visual como el medio que nos permite acceder al conocimiento: uno, mediado (per speculum in aenigmate); dos, inmediato (facie ad faciem). Esta visión facial, que en el platonismo inicial se identifica con la mirada directa al sol, supone la recepción de la sabiduría a través de la contemplación del Bien. Así, tenemos este primer espejo de Narciso, que correspondería en la teología de una Marguerite Porete a un entendimiento per aespeculum, es decir, a una comprensión, a un conocimiento o saber a través de la mediación, es decir, de las capacidades humanas (sensoriales, intelectuales, lingüísticas, incluso amatorias) que, en suma, se relacionarían con una inclinación eminentemente humana del alma. Este espejo, como hemos dicho, sería el propio Mirouer, cuyo mayor peligro es el de llegar a ser idolátrico: el de pasar de ser medio a ser fin. Por otro lado, existe otro espejo posible, que no es otro que Dios concebido como tal ${ }^{43}$ :

Sobre el trono de Dios no hay nada sino Dios, Dios, Dios. Dios infinitamente vasto. Arriba sobre el trono, se puede ver el espejo de la Divinidad, el parecido de la Humanidad, la luz del Espíritu Santo y se comprende cómo esos tres son uno en Dios y cómo ellos caben en uno. No soy capaz de decir nada más sobre esto.

Unirse a ese espejo último, que en otro pasaje Mechthild denomina Spiegelberg (es decir, Espejomontaña) ${ }^{44}$, será la meta de la mayoría de itinerarios espirituales trazados por estas autoras ${ }^{45}$. ¿Cómo se traspasa este espejo eterno o, mejor, volviendo a Coccia, cómo ser el reflejo de un espejo lúcido? La pregunta tiene una connotación fundamental relacionada con el conocimiento al que aspira no solo el contemplativo sino, como da cuenta el mito del pecado original y la expulsión del Paraíso cualquier ser humano e incluso cualquier ángel (pensemos que esta fue la razón por la que Lucifer queda atascado en el Cocito dantesco, que, en cierta manera, también es un espejo).

Desde el punto de vista filosófico-teológico que hemos visto, ese proceso de purificación se explica a través del paso de la imagen de la primera cámara del cerebro, la imaginativa, a la racional, donde lo meramente perceptivo se intelectualiza:

42 I Cor, 13, 12.

43 «Ob dem gottes thron ist nit me denne got, got, got, unmesselichen grosser got. Oben in dem throne siht man den spiegel der gotheit, das bilde der menscheit, das lieht des heligen geistes und bekennet, wie die drie ein got sint, und wie si sich fügent in ein. Niht mere mag ich hievon sprechen». M. von Magdeburg, Fliessende Licht der Gottheit, ed. Hans Neumann, vol. I, Artemis, 1990, III, 1. La traducción al castellano es mía.

${ }^{44}$ M. von Magdeburg, Fliessende Licht der Gottheit, I, 20. V., a su vez, M. Viller et al., Dictionnaire de Spiritualité ascétique et mistique. Doctrine et Histoire. Paris, Beauchesne, 1937, vol. 10, s. v. «Miroir», columna 1296.

45 Nos encontramos con una imagen que existe en diversas tradiciones religiosas, v. AgAMBEN, Estancias, p. 155. 
desde un punto de vista medieval pasamos de conocer a través de las sombras (per aespeculum in aenigmate) a convertir en luz el conocimiento, aunque en cierto sentido siga siendo sombría, pues hablamos de intelectualidad humana. ¿Dónde se produce la unión entre el cuerpo y el alma? Aquí tenemos que acudir de nuevo al neoplatonismo, porque ese lugar tiene una definición clara a partir, al menos, de Plotino, que lo llamó centro del alma; igual que después otros lo denominarían mens (Agustín de Hipona o Guillaume de Saint Thierry) ${ }^{46}$, apex mentis (Hugo de San Víctor) o Grunt, fondo sin fondo (Eckhart). La dimensión paradójicamente negativa (ya que estamos ante un "espacio" que representa el lugar supremo del alma, pero a la vez una caída) da cuenta, entre otras cosas, de la necesidad de una renuncia como purificación en el caso de la mística femenina bajomedieval ${ }^{47}$. Es un lugar en todo caso sin amor, porque el amor ha fluido, ha realizado su papel de atracción, de motor y de goce, y quedarnos en ese goce quedaría en un acto puramente idolátrico. La contemplación face ad faciem es, pues, única forma de conocimiento real, no mediada.

En todo caso, para hablar de ese lugar del alma que nos conecta con la divinidad, debemos acudir a los desarrollos de la teología del siglo XII en adelante concernientes a la idea de que el hombre fue concebido «a imagen y semejanza» («ad imaginem et similitudinem ${ }^{48}$ ) de Dios. Por supuesto, la exégesis de este pasaje del Génesis no carece de grandes complicaciones y variantes, que Javelet mostró magistralmente en su libro dedicado al tema ${ }^{49}$. Sin embargo, si nos acercamos al capítulo que el mismo Javelet dedica a situar metafísicamente esa imagen de Dios impresa en el alma del hombre, nos daremos cuenta de que existe una tradición al menos desde Agustín, que recorre el siglo XII de mano de los cistercienses y que llega a nuestras beguinas a través de los mismos que «sitúa la imagen de Dios en la 'mens'», es decir, en "la parte superior de la razón», "la cima del alma» o «lo supremo del alma " ${ }^{50}$. En todo caso, en el interior del hombre, fuera de la imaginación y casi fuera de la razón.

Estamos aquí ante un nuevo espejo, que el alma de cada uno de nosotros contiene. Un espejo que está manchado por el pecado (por ello, no podemos conocer directamente a Dios sin un proceso de purificación previo) y que debemos, de nuevo, desnudar, limpiar, clarificar para poder reflejarnos en él. Este espejo representa la esperanza platónica de la posibilidad de retorno a Dios de cualquier ser humano, que, simplemente por serlo, posee la impresión divina en su interior (y aquí deberíamos referirnos al Maestro Eckhart como el teorizador por excelencia del nacimiento

${ }^{46}$ JaVELET, Image et Ressemblance, p. 177.

47 V. Cirlot, «La mística femenina medieval, una tradición olvidada», en V. Gómez I Oliver (coord.), Oculto pero invisible: voces femeninas, Barcelona, Publicacions de la residència d'investigadors, 29, 2006, pp. 85-96.

${ }_{48}$ Gn 1, 26.

49 R. Javelet, Image et Ressemblance au douzième siecle. De Saint Anselme a Alain de Lille, Strasbourg, Éditions Letouzey \& Ané, 1967.

50 Idem, pp. 176-181. 
de Dios en el alma, pero el tiempo no nos los permite) ${ }^{51}$. Como en la escala de Diotima arriba citada, el primer impulso debe partir del deseo corporal, pero el proceso de purificación no puede hacerse esperar. El hombre debe devenir Dios a través de esa pequeña puerta especular que la divinidad ha dejado entreabierta en su alma. Solo así el ser humano podrá parecerse a los seres de la creación que más se parecen a Dios: los ángeles ${ }^{52}$. Y aquí aludimos a una imagen típica de estas autoras: aquella de la mujer seráfica o la mujer serafín. En palabras de Mechthild de Magdeburg ${ }^{53}$ :

Aquellos que arden en el fuego del amor verdadero y construyen en el firme terreno de la verdad y dan abundante fruto para un bendito final, ellos habitan en las alturas. Glosa: esto habla sobre el serafín.

Hablar de mujer-ángel es apuntar a la que sería, precisamente, la meta de muchos de los escritos de estas autoras beguinas. Como sabemos, sus textos plantean la simplificación de naturalezas, es decir, la posibilidad de retornar a un estado en el que nuestra alma no había sido separada aún de la Divinidad. Esta transformación de los amantes nos habla, en algún grado, precisamente de serafinidad: si el alma humana consigue llegar a la perfección, se identificará con el coro angélico más cercano a la Trinidad, ya que los serafines son aquellos seres puramente intelectuales que reciben más directamente el amor de Dios y arden en consecuencia, a la vez que lo transmiten al cosmos creado. El alma estaría, así, consiguiendo retornar a su naturaleza angélica, a ser un ángel (pues todos, de alguna manera, somos ángeles sucios o ensuciados por estar encerrados en un cuerpo $)^{54}$.

La pregunta que nos interesa aquí es, en primer lugar, si en los textos de la mística bajomedieval femenina se plantea que el ser humano pueda llegar a ser más que un serafín, ¿se puede dar ese paso abismal que separa a los serafines, inflamados por el amor divino, de Dios? Aquí es cuando debemos atravesar el espejo y la mejor manera de hacerlo es acudir a los estados quinto y sexto de la escala de perfeccionamiento de Marguerite Porete. La negación del espejo de Narciso en el Mirouer des simples ames se da a través de una imagen de descenso que, reitero, es fundamental en la tradición mística femenina de la época y que apunta a la vía negativa. En el caso de Marguerite se habla de la necesidad no tanto de soportar como de realizar

51 Vale la pena consultar su noción de Bild, absolutamente neoplatónica, como la única forma de reconectarse con la divinidad, v. M. EchKart, El fruto de la nada, trad. A. Vega, Madrid, Siruela, 1998, p. 68.

52 Sobre los ángeles y los espejos: M. VILler et al, Dictionnaire de Spiritualité ascétique et mistique. Doctrine et Histoire, Paris, Beauchesne, 1937, vol. 10, s. v. «Miroir», columna 1297.

53 «Die da brinnent in der waren minne und uf einen steten grunt buwent der warheit und fruht bringent mit vollem huffen des seligen endes, die wonent in der hơhin. // Glosa: das ist úber Seraphin». Mechthild von Magdeburg, Fliessende Licht der Gottheit, ed. Hans Neumann, vol. I. Artemis, 1990, i: 9, 13. La traducción castellana es mía.

54 JaVELET, Image et Ressemblance, pp. 162-166. 
cuatro caídas. En síntesis ${ }^{55}$ : «Su voluntad es nuestra, pues ha caído de la gracia en la perfección de las obras de las Virtudes, y de las Virtudes en Amor, y de Amor en nada, y de nada en claridad de Dios, viéndose con los ojos de su majestad...».

Estamos aquí ante un rasgo de la tradición beguinal: la apófasis o, como ya he dicho, la vía negativa. Como podemos ver, estas cuatro caídas suponen cuatro hitos esenciales en el camino-experiencia del Alma que ya ha traspasado un grado de perfección determinado: su importancia se clarifica si las ponemos en relación con los distintos estados. Vistas a esta luz, solo diremos que son necesarias tres caídas (de gracia en perfección de las Virtudes, de esta en Amor, de este en Nada) para realizar el propósito fundamental que Marguerite se propone con este libro: reconducir los pasos extraviados hacia la apófasis y la posterior experiencia de la divinidad, que la llevará a la deificación. En efecto, tanto la caída de las virtudes en Amor como la ulterior caída de Amor en Nada preparan al Alma para el sexto estado, donde se transformará, lo que conlleva su subsiguiente vida de paz como el mayor don divino que pueda recibirse en vida corporal.

Fijémonos en que en la última caída de la cita, "de Nada en claridad de Dios», existe una mirada especular: «Viéndose con los ojos de su majestad». Esto es así porque también en el tratado de Marguerite, Dios es concebido como un espejo y el ascenso-descenso del alma hacia él no es otra cosa que un juego de reflejos en los que el alma desea conocerse, reconocerse y en el que, poco a poco, se va aclarando la imagen. No tengo espacio para hacerlo aquí, pero un análisis pormenorizado de los últimos grados de perfeccionamiento del camino propuesto por Marguerite (explicados con detalle en su famoso capítulo 118) nos podrían convencer de hasta qué punto estas caídas y este reflejo están relacionados ${ }^{56}$ : primero, con el autoconocimiento; segundo, el anonadamiento (con el vaciamiento absoluto de todo elemento mediador entre el sujeto y la divinidad); tercero, con la consecución de la identidad del alma con Dios.

En efecto, en el quinto estado el alma se mira en un espejo y allí se da cuenta de que ella es pura Maldad, mientras que Dios es pura Bondad. Esta toma de conciencia de su bajeza hace que su imagen desaparezca del espejo, pues se comienza a considerar nada frente al todo, al único Ser, que es Dios. Este primer proceso, que es el del que denominaba arriba autoconocimiento, acaba con las siguientes palabras «... [la divinidad] la ha ultimado al mostrarle a ella misma. Ahora ve por ella» ${ }^{57}$. El alma se ha podido reconocer en su nulidad al enfrentarse a su creador y el resultado

55 «Sa voulenté est nostre, car elle est cheue de grace en parfection de l'ouvre des Vertuz, et des Vertuz en Amour, et d'Amour en Nient, et de Nient en Clarifiement de Dieu, qui se voit des yeulx de sa majesté...", M. Porete, Le mirouer des simples ames / Speculum simplicium animarum, ed. Romana Guarnieri / Paul Verdeyen, Turhnout, Brepols, 1986. La traducción española está tomada de M. Porete, El espejo de las almas simples, trad. B. Garí, Madrid, Siruela, 2005, pp. 140-141.

${ }^{56}$ Para un análisis pormenorizado de este capítulo a través de la imagen especular, v. C. Müller, Marguerite Porete et Marguerite d'Oingt de l'autre côté du miroir, New York, Peter Lang, 1999 , p. 31 y ss.

${ }_{57}$ M. Porete, El espejo de las almas simples, trad. B. Garí, Madrid, Siruela, 2005. 
es preclaro: es Dios quien mira a través de sus ojos, porque es ella misma. El sexto estado confirma lo dicho: ella sigue sin verse en el reflejo del espejo, pues ya no es ni siquiera ella la que mira. Es la divinidad, desde dentro del espejo, la que la mira (y entonces ella sí se ve): la paradoja es flagrante: «... [el alma] no ve ni a Dios ni a ella, sino que Dios se ve a sí mismo en ella, por ella, por ella y sin ella [...] $\aleph^{58}$. Llegada a este estado, el alma se da cuenta de que ha penetrado en el espejo y de que, efectivamente, ha sido deificada.

\section{CONCLUSIONES}

He querido articular en estas páginas una serie de análisis que nos permitiera aclarar la presencia del espejo en los escritos de las místicas beguinas de los siglos XIII y XIV, preguntando indirectamente el porqué de la inexistencia de mitos clásicos en ellas. Como hemos visto, esa inexistencia es relativa, pues nos basta acercarnos con ojos entrenados a los textos para reconocer imágenes populares en la época que, en el fondo, se usan a través de la subversión. Es el caso de la fuente del amor fantasmático, aquella de Narciso, la fuente peligrosa, la primera y necesaria fuente en un itinerario hacia la divinidad: aquella que, a través de los impulsos de los sentidos unidos al amor divino, nos permite avanzar en nuestro desarrollo espiritual. En efecto, es la imaginación un mal necesario que encontramos en los manuales devocionales que hablan de la oración interior, incluso en aquellos de Juan de la Cruz y Teresa de Jesús, herederos, sin duda, de este tipo de espiritualidad.

Si la fuente de Narciso estaba ligada al imaginario cortés, la idea del Diosfuente, del Dios que fluye y que es en sí también un espejo, hunde sus raíces en el neoplatonismo, que necesita de una mitología para dar cuenta del retorno del alma a lo increado. A pesar de que los paralelismos entre el neoplatonismo de, pongamos, un Plotino y sus transformaciones cristianas parecen claras, las segundas se encuentran despojadas de los mitos clásicos tomados de manera alegórica. $\mathrm{O}$ bien se prefieren imágenes puramente cristianizadas (un peregrino frente a Ulises), o bien se elige el lenguaje nupcial. En el cristianismo a partir del siglo XII esa mitología del retorno tiene una formalización muy clara en las teologías de la imagen y la semejanza, que han sido bien estudiadas sobre todo a partir del libro de Javelet. Estas, además de estar relacionadas con una concepción común de la percepción, del cerebro y del alma, componen también relatos en los que el espejo se esconde. En este caso no en otro lugar sino en el punto más inaccesible del alma. Es allí donde, según las autoras que hemos estudiado, nos espera un Dios con forma de espejo que no refleja a nadie más que a nosotros mismos. 